\title{
Properties of UFG HSLA Steel Profiles Produced by Linear Flow Splitting
}

\author{
Enrico Bruder ${ }^{\mathrm{a}}$, Tilman Bohn ${ }^{\mathrm{b}}$ and Clemens Müller ${ }^{\mathrm{c}}$ \\ Division Physical Metallurgy, Technische Universität Darmstadt, \\ Petersenstrasse 23, 64287 Darmstadt, Germany \\ ae.bruder@phm.tu-darmstadt.de, bt.bohn@phm.tu-darmstadt.de, \\ cc.mueller@phm.tu-darmstadt.de
}

Keywords: Linear flow splitting, Severe deformation, Ultrafine grains, HSLA steel, Mechanical properties, Thermal stability

\begin{abstract}
Linear flow splitting is a new cold forming process for the production of branched sheet metal structures. It induces severe plastic strain in the processing zone which results in the formation of an UFG microstructure and an increase in hardness and strength in the flanges. Inbuilt deformation gradients in the processing zone lead to steep gradients in the microstructure and mechanical properties. In the present paper the gradients in the UFG microstructure and the mechanical properties of a HSLA steel (ZStE 500) processed by linear flow splitting are presented, as well as a calculation of local strength from hardness measurements on the basis of the Ludwikequation. In order to investigate the thermal stability of the UFG microstructure heat treatments below the recrystallization temperature were chosen. The coarsening process and the development of the low angle to high angle grain boundary ratio in the gradient UFG microstructure were monitored by EBSD measurements. It is shown that heat treatment can lead to a grain refinement due to a strong fragmentation of elongated grains while only little coarsening in the transverse direction occurs. A smoothing of the gradients in the UFG microstructure as well as in the mechanical properties is observed.
\end{abstract}

\section{Introduction}

Linear flow splitting is a new cold forming process for the production of bifurcated integral profiles from sheet metal. The tooling system consists of an obtuse angled splitting roll and two supporting rolls (Fig. 1). The final profile geometry originates from several discrete forming steps in which the splitting roll drives into the band edge by an incremental splitting depth yinc. High hydrostatic stresses in the processing zone prevent the formation of cracks and allow a high total splitting depth $\left(\mathrm{y}_{\text {tot }}\right)$. Linear flow splitting can be conducted either in a reversing process with a single roll stand or integrated in a mill train for continuous processing. Further details on the process principle and possible applications are presented elsewhere [1,2].

Earlier investigations have shown that linear flow splitting induces severe plastic strain which leads to the formation an ultrafine grained (UFG) microstructure in the regions of strongest plastic deformation, i.e. the splitting center and the flange surface [3]. In contrast to typical severe plastic deformation (SPD) processes as equal-channel angular pressing (ECAP) [4,5] or high pressure torsion (HPT) [5,6], linear flow splitting is characterized by inbuilt deformation gradients in the processing zone and a change in geometry of the semi-finished part. Though, the intention of the process is the production of integral sheet metal profiles with bifurcations and not bulk UFG material. However, a closer investigation of the gradient UFG microstructure and its mechanical properties is of great interest in respect of further processing steps and possible applications of the profiles. Considering subsequent joining operations or applications at elevated temperatures, the thermal stability of the microstructure and mechanical properties becomes an important issue. Therefore this article concentrates on the description of the microstructural gradients, the mechanical properties and their thermal stability. 

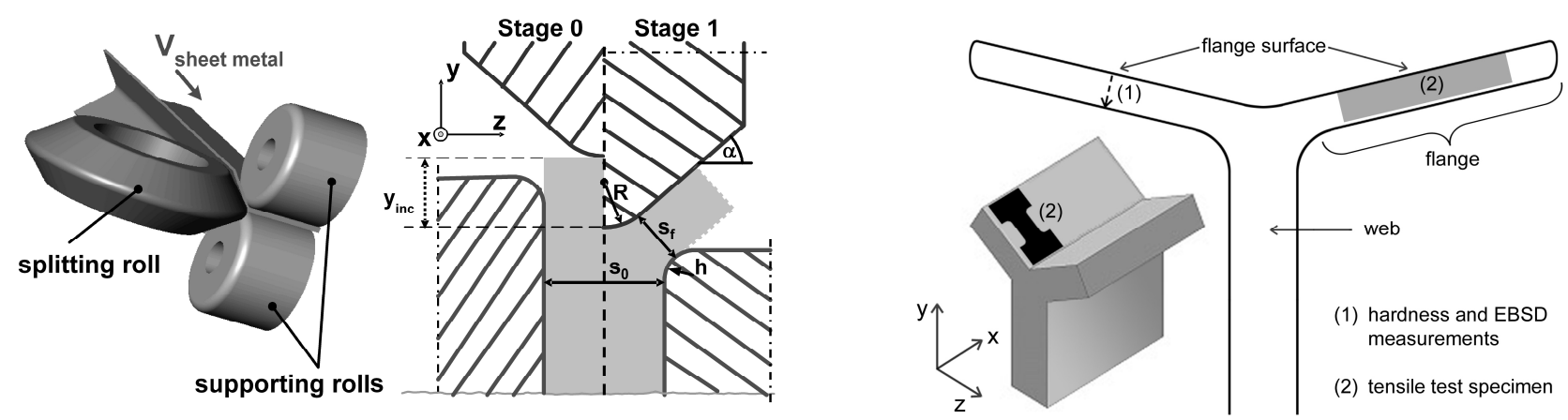

Fig. 1. Process principle of linear flow splitting (left) and profile scheme (right).

\section{Experimental}

The material used in this investigation is a HSLA sheet steel of the grade ZStE $500(0.07 \mathrm{wt} \% \mathrm{C}$, $0.71 \mathrm{wt} \% \mathrm{Mn}, 0.1 \mathrm{wt} \% \mathrm{Cr}, 0.047 \mathrm{wt} \% \mathrm{Si}, 0.034 \mathrm{wt} \% \mathrm{Nb}$ and $0.016 \mathrm{wt} \% \mathrm{Al})$ with a thickness $\left(\mathrm{s}_{0}\right)$ of $2 \mathrm{~mm}$. Its microstructure consists of equiaxed ferrite grains with small cementite precipitations located at the grain boundaries. The average grain size of the sheet material measured by optical microscopy was $\sim 6 \mu \mathrm{m}$. Linear flow splitting was conducted at the Institute for Production Engineering and Forming Machines (Technische Universität Darmstadt) in a reversing process to a total splitting depth $\left(\mathrm{y}_{\mathrm{tot}}\right)$ of $20 \mathrm{~mm}$ with an incremental splitting depth $\left(\mathrm{y}_{\text {inc }}\right)$ of $1 \mathrm{~mm}$, a flange thickness $\left(\mathrm{s}_{\mathrm{f}}\right)$ of $\sim 1 \mathrm{~mm}$ and an angle of the flanges $\alpha=10^{\circ}$. Heat treatments were carried out in a tube furnace under argon atmosphere for $15 \mathrm{~min}$ at temperatures of $450{ }^{\circ} \mathrm{C}$ and $550{ }^{\circ} \mathrm{C}$. The temperatures were selected on the basis of preliminary investigations which showed that heat treatments up to $300{ }^{\circ} \mathrm{C}$ did not influence the microstructure or mechanical properties while discontinuous recrystallization occurs above $580{ }^{\circ} \mathrm{C}$.

Samples for Electron Backscatter Diffraction (EBSD) and hardness measurements were taken perpendicular to the splitting direction. EBSD measurements were carried out using a FEG SEM fitted with a TSL EBSD system. Low angle grain boundaries (LAGBs) have been defined between $2^{\circ}$ and $15^{\circ}$ misorientation and high angle grain boundaries (HAGBs) above a misorientation of $15^{\circ}$. Hardness profiles on the cross section of the profiles were measured by the Vickers method with a load of $50 \mathrm{~g}$. Tensile test specimens were cut from the flanges as shown in Fig. 1 with a gauge length of $3 \mathrm{~mm}$, a gauge width of $2 \mathrm{~mm}$ and a thickness of $0.8 \mathrm{~mm}$. (The tensile test specimens of the initial sheet material had the same dimension to maintain comparability.) In order to determine the mechanical properties of the upper (severely deformed) and lower (moderately deformed) side of the flanges some specimens were reduced in thickness to $0.4 \mathrm{~mm}$ by grinding the upper or lower side of the flange, respectively. Tensile tests were carried out at an initial strain rate of $8 \times 10^{-4} \mathrm{~s}^{-1}$ with a constant crosshead velocity.

\section{Results}

Linear flow splitting leads to an UFG microstructure in the splitting center and accordingly the flange surface area. Due to the preferential flow direction of the material perpendicular to the splitting direction (x-axis in Fig. 1) a pancake like UFG microstructure develops, thus the grain dimensions in the flanges are strongly dependent on the direction which is exemplarily shown in Fig. 2 for a position $50 \mu \mathrm{m}$ underneath the flange surface. It shows a pancake microstructure with maximum grain dimensions parallel to the z-axis and minimum parallel to the y-axis. The following micrographs concentrate on the $\mathrm{y} \times \mathrm{z}$ plane as it includes these two directions. Although the structure in the $\mathrm{x} \times \mathrm{z}$ plane is comparatively coarse its area-related average grain size is still less than $1 \mu \mathrm{m}$.

Investigations on the microstructure of the as rolled flanges along the y-axis reveal a gradient which is presented in Fig. 3 by example EBDS maps. The elongated grains near the surface are mostly 


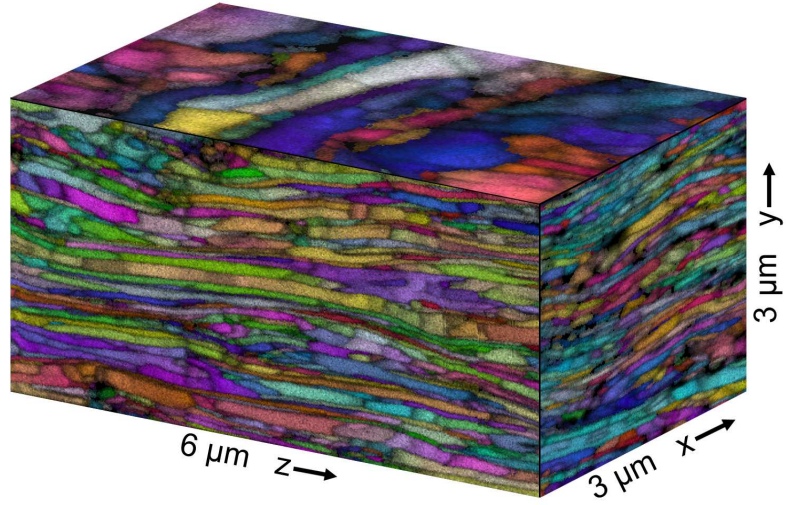

Fig. 2. EBSD maps (image quality + inverse pole figure) of the planes perpendicular to the $\mathrm{x}-, \mathrm{y}$ - and $\mathrm{z}$ axis $50 \mu \mathrm{m}$ underneath the flange surface (as rolled).
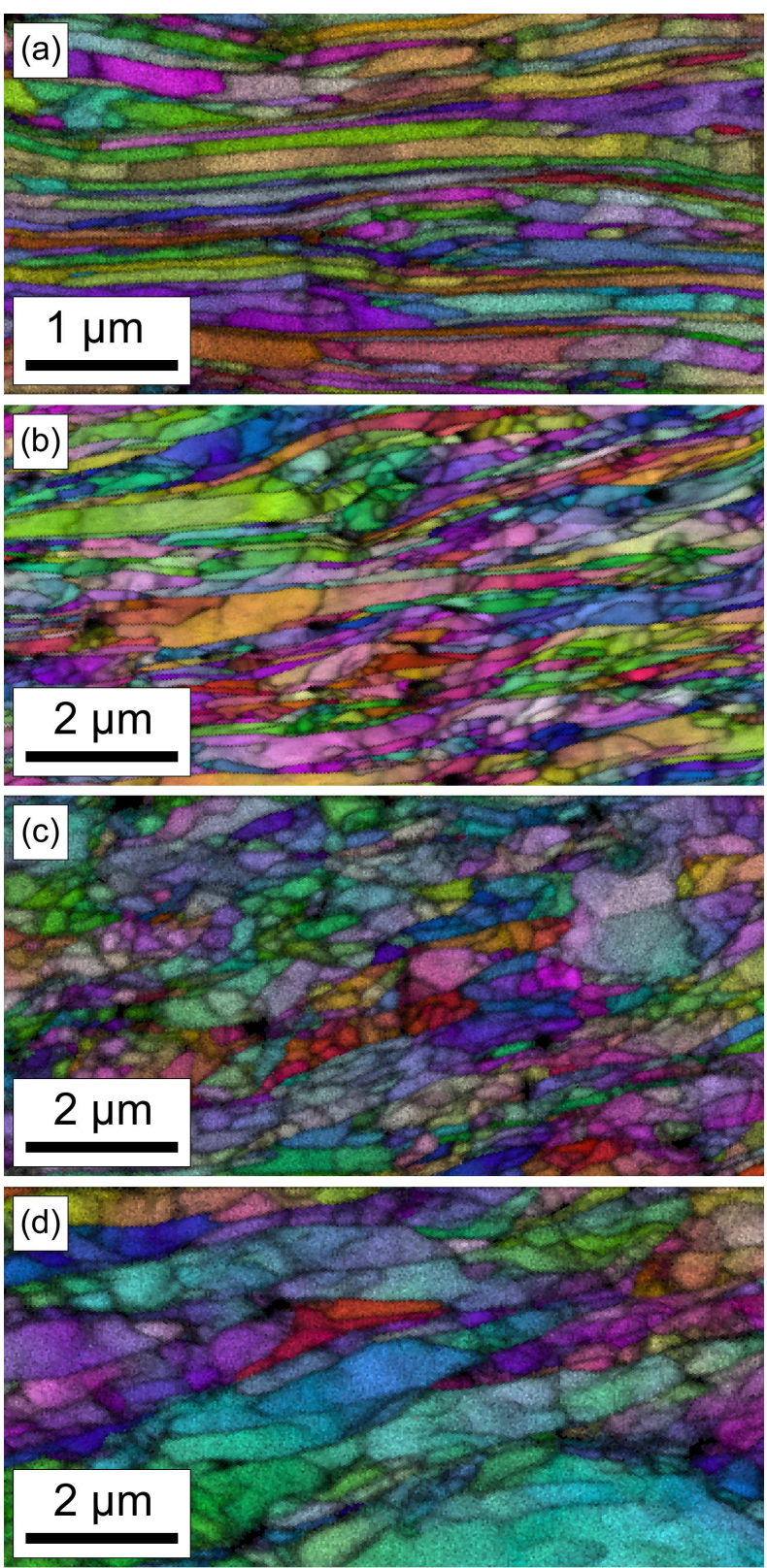

Fig. 3. EBSD maps of the as rolled condition (image quality + inverse pole figure) with different distances to the flange surface: (a) $50 \mu \mathrm{m}$, (b) $250 \mu \mathrm{m}$, (c) $450 \mu \mathrm{m}$, (d) $650 \mu \mathrm{m}$. separated by HAGBs and show only marginal fragmentation. Within $50 \mu \mathrm{m}$ to the flange surface the average grain dimensions (line intersection) along the $y$-axis are below $100 \mathrm{~nm}$. With increasing depth, i.e. distance to the split surface, the grain structure becomes coarser and more equiaxed. The average (area-related) grain size increases with growing distance to the flange surface from less than $0.3 \mu \mathrm{m}$ to approximately $1.2 \mu \mathrm{m}$ and is associated with a decreasing fraction of HAGBs from $82 \%$ close to the flange surface to $31 \%$ at the lower side of the flange (Fig. $4)$. There are no gradients in the microstructure parallel to the flanges except for the flange tip (about $4 \mathrm{~mm}$ in length) and also no gradients along the splitting direction thus Figs. $2-4$ are representative for a large part of the flanges.

Fig. 5 shows the microstructure perpendicular to the splitting direction after annealing for $15 \mathrm{~min}$ at $450{ }^{\circ} \mathrm{C}$ and $550{ }^{\circ} \mathrm{C}$, respectively. Comparing Figs. 3 and 5 reveals that the elongated grains near the flange surface (see Fig. 3a) tend to fragment during annealing (see Figs. 5a, 5c), i.e. grain dimensions decrease at these temperatures. This is accompanied by a coarsening process in the transverse direction which is hardly perceptible at $450{ }^{\circ} \mathrm{C}$ but very distinct at $550{ }^{\circ} \mathrm{C}$, compare Figs. $5 \mathrm{a}$ and $5 \mathrm{c}$. The gradients in grain size and percentage of HAGBs for the annealed conditions are shown in Fig. 6. At $450{ }^{\circ} \mathrm{C}$ a smoothing of the gradients in grain size and HAGB fraction is observed. This effect is due to a grain refinement (area-related) during heat treatment in a zone between $200-800 \mu \mathrm{m}$ below the surface (see Fig. 6a). Annealing at $550{ }^{\circ} \mathrm{C}$ results in a nearly homogeneous microstructure throughout the flange

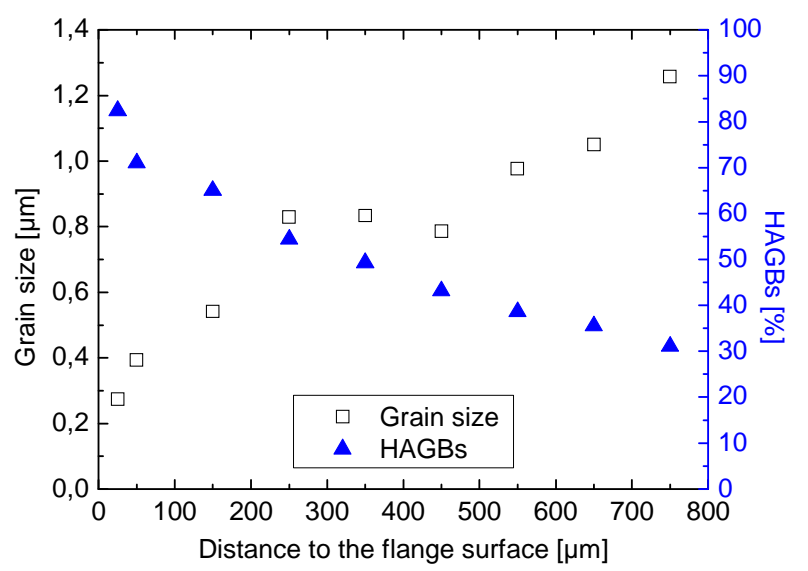

Fig. 4. Area-related grain size and percentage of HAGBs perpendicular to the flange surface (as rolled). 

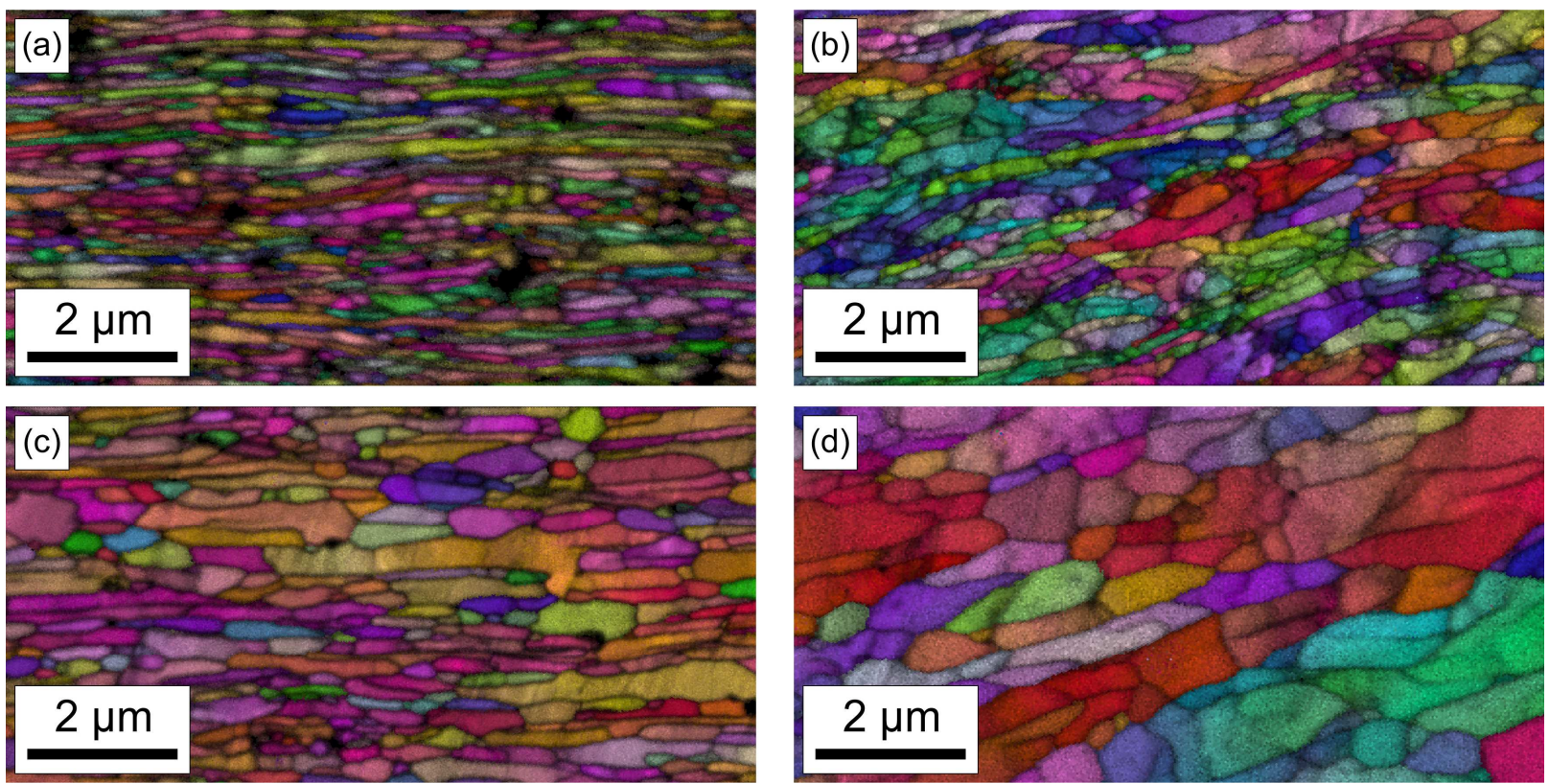

Fig. 5. EBSD maps after annealing with different distances to the flange surface: (a) $50 \mu \mathrm{m}-15 \mathrm{~min}$ at $450{ }^{\circ} \mathrm{C}$, (b) $450 \mu \mathrm{m}-15 \mathrm{~min}$ at $450{ }^{\circ} \mathrm{C}$, (c) $50 \mu \mathrm{m}-15 \mathrm{~min}$ at $550{ }^{\circ} \mathrm{C}$, (d) $450 \mu \mathrm{m}-15 \mathrm{~min}$ at $550{ }^{\circ} \mathrm{C}$.
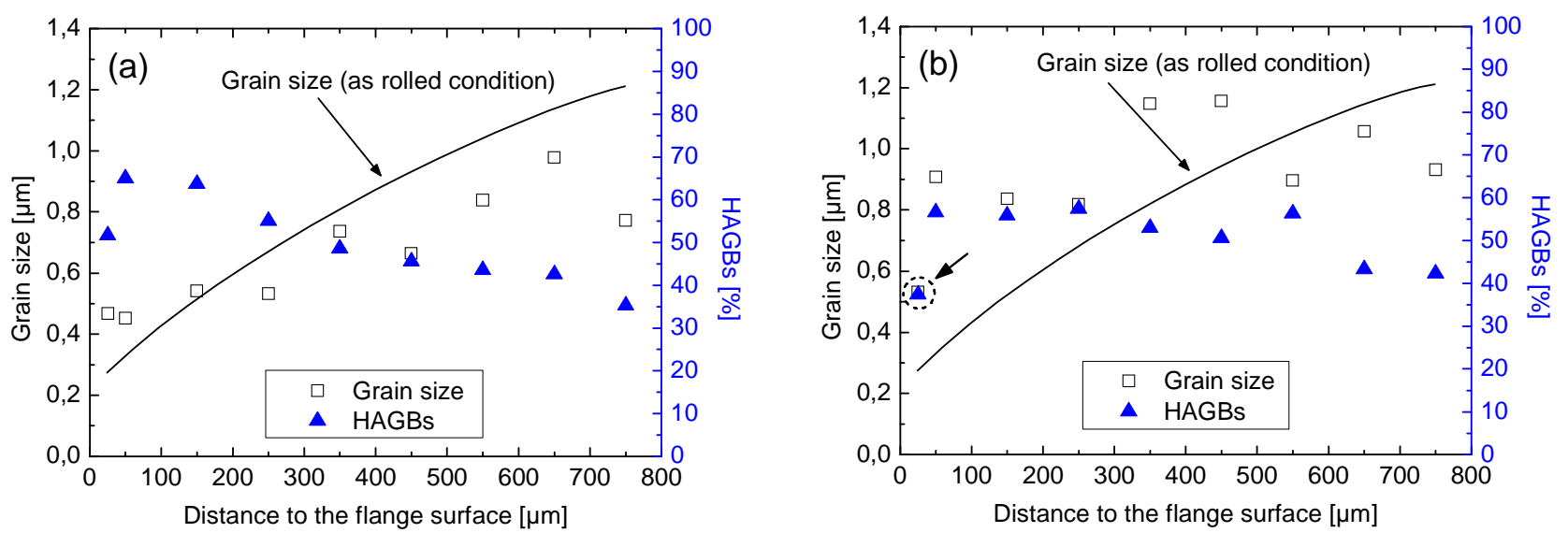

Fig. 6. Area-related grain size and percentage of HAGBs perpendicular to the flange surface after annealing: (a) $15 \mathrm{~min}$ at $450{ }^{\circ} \mathrm{C}$, (b) $15 \mathrm{~min}$ at $550{ }^{\circ} \mathrm{C}$.

with larger grains than in the as rolled condition $(\sim 1 \mu \mathrm{m}$ average grain size $)$ and a roughly constant percentage of HAGBs $(\sim 50 \%)$. An interesting exception is the significantly smaller grain size combined with a small fraction of HAGBs $25 \mu \mathrm{m}$ underneath the surface (see arrow in Fig. 6b).

The hardness distributions perpendicular to the flange surface for all investigated conditions are shown in Fig. 7. The hardness decreases with increasing depth from 345 HV0.05 to 245 HV0.05 in the as rolled condition while the gradient is especially steep within $200 \mu \mathrm{m}$ underneath the flange surface. Annealing at $450{ }^{\circ} \mathrm{C}$ results in an overall decrease in hardness and a smoothing of the gradient. At $550{ }^{\circ} \mathrm{C}$ the hardness gradient turns into a plateau at a level of $230 \mathrm{HV} 0.05$ that is well above the initial hardness. Hence it is possible to reduce or annihilate the hardness gradient via annealing while maintaining superior strength compared to the initial sheet material.

Tensile tests reveal an increase in yield and tensile strength (744 MPa and $782 \mathrm{MPa}$ ) of about $60 \%$ in the as rolled condition compared to the initial sheet material (Fig. 8). The increased strength is associated with a reduced fracture strain and marginal uniform elongation. Both annealing treatments lead to a decrease in strength but an increase in ductility, which is more pronounced at $550{ }^{\circ} \mathrm{C}$. Note: The yield drop of both annealed conditions is an interesting phenomenon that has also been reported for UFG 1100-Al and UFG IF steel produced by accumulative roll bonding [7] but has not been clarified yet. 


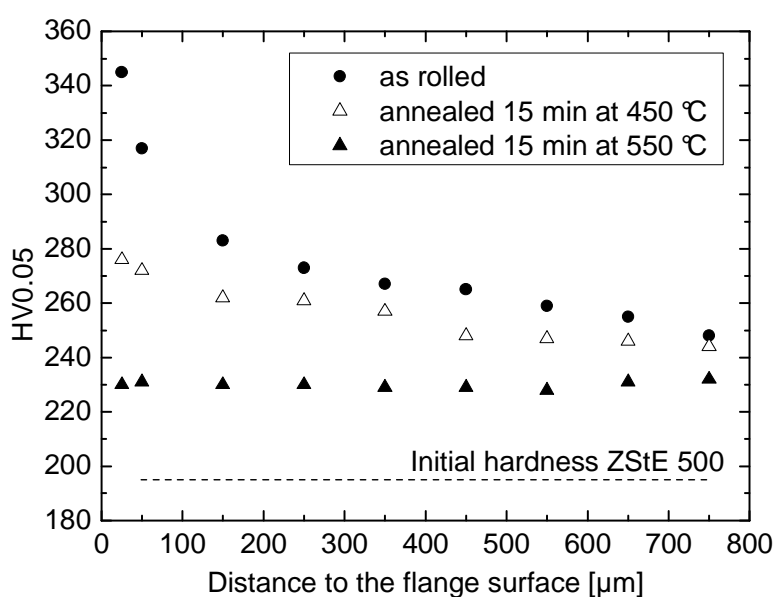

Fig. 7. Hardness distribution perpendicular to the flange surface.

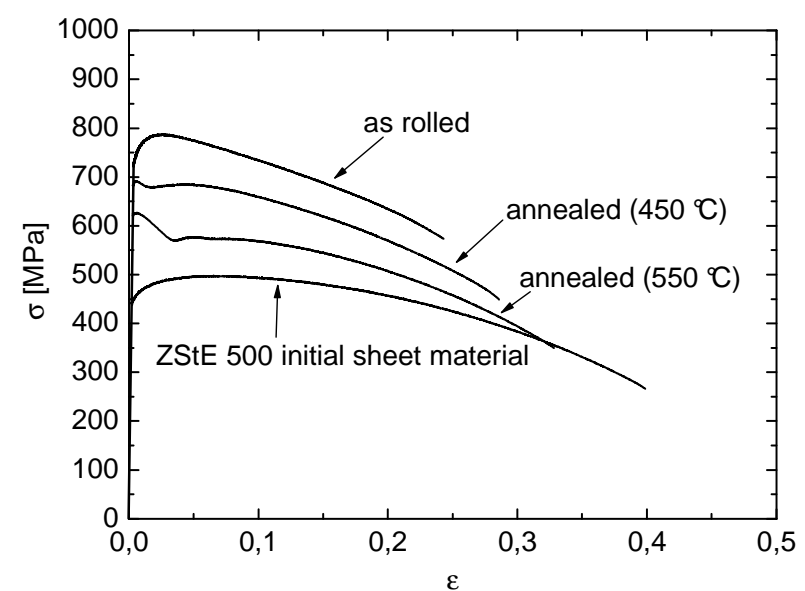

Fig. 8. Engineering stress-strain curves.

\section{Discussion}

The results show that linear flow splitting generates an UFG pancake microstructure with steep gradients. This structure is stable up to $300{ }^{\circ} \mathrm{C}$ whereas at $450{ }^{\circ} \mathrm{C}$ and $550{ }^{\circ} \mathrm{C}$ a fragmentation and a coarsening of the pancake structure occurs. An examination of the area-related grain size averaged across the flange from the upper to the lower side reveals an overall decrease from $0.83 \mu \mathrm{m}$ in the as rolled condition to $0.69 \mu \mathrm{m}$ after annealing at $450{ }^{\circ} \mathrm{C}$ for $15 \mathrm{~min}$, which is surprising at first glance. The EBSD maps show that the grain refinement is most likely not induced by a discontinuous recrystallization, due to the fact that the elongated grains tend to fragment along the $\mathrm{z}$-axis while the grain dimensions in the y-axis are nearly retained. However, the formation of new boundaries seems probable considering the simultaneous decrease in hardness in spite of the smaller grain dimensions. This implies a significant reduction of the dislocation density. Hence, the formation of new grain boundaries during annealing is presumably caused by a rearrangement of dislocations, though this assumption needs to be confirmed by further investigations.

The increased strength as well as the marginal strain hardening and uniform elongation shown by the tensile tests are characteristic for UFG metals $[5,7,8,9]$. In contrast to homogenous bulk UFG metals it is impossible to relate strength and local microstructure on the basis of tensile tests, as the whole microstructural gradient is covered by the tensile specimens. Thus, the local strength can only be calculated from the hardness. Earlier investigations on the correlation of hardness and yield strength in bifurcated HSLA steel profiles processed by linear flow splitting led to an empirical

Table 1

Calculated and measured yield strength.

\begin{tabular}{cccc}
\hline $\begin{array}{l}\text { location of } \\
\text { specimen* }\end{array}$ & condition & $\begin{array}{c}\sigma_{\mathrm{ys}}(\text { calc. }) \\
{[\mathrm{MPa}]}\end{array}$ & $\begin{array}{c}\sigma_{\mathrm{ys}}(\mathrm{meas} .) \\
{[\mathrm{MPa}]}\end{array}$ \\
\hline $0-800 \mu \mathrm{m}$ & as rolled & 755 & 744 \\
$0-400 \mu \mathrm{m}$ & as rolled & 803 & 789 \\
$400-800 \mu \mathrm{m}$ & as rolled & 707 & 682 \\
$0-800 \mu \mathrm{m}$ & $15 \mathrm{~min}-450^{\circ} \mathrm{C}$ & 698 & 697 \\
$0-800 \mu \mathrm{m}$ & $15 \mathrm{~min}-550^{\circ} \mathrm{C}$ & 618 & 624 \\
\hline
\end{tabular}

*) Region covered by the thickness of the specimen referred to the flange surface equation derived from the well known Ludwik-equation [3]:

$$
\sigma_{y s}=3.36 \times H V-155
$$

Table 1 shows the good compliance between measured and calculated yield strength with a maximum deviation of less than $4 \%$. Thus the strength in the region with the smallest grain size close to the flange surface can be calculated with adequate accuracy to $\sim 1000 \mathrm{MPa}$.

The results of the hardness measurements and tensile tests show that the strength is not only influenced by the grain size (hall-petch). The decrease in hardness and yield strength despite the smaller grain size after annealing at $450{ }^{\circ} \mathrm{C}$ indicates a high dislocation density, i.e. work hardening in the as rolled condition. Thus the relief of work hardening during annealing dominates the 
strengthening effect of grain refinement. The decrease in yield strength is combined with an increased elongation to failure which also indicates a reduced dislocation density. However, the grain size effect on the strength becomes transparent by comparing the annealed conditions. The yield strength drops from $697 \mathrm{MPa}$ after annealing at $450{ }^{\circ} \mathrm{C}$ to $624 \mathrm{MPa}$ after annealing at $550{ }^{\circ} \mathrm{C}$, while the average grain size between upper and lower side of the flange increases from $0.63 \mu \mathrm{m}$ $\left(450{ }^{\circ} \mathrm{C}\right)$ to $0.92 \mu \mathrm{m}\left(550^{\circ} \mathrm{C}\right)$. Assuming that the dislocation density in both annealed conditions is nearly constant, this effect is basically a result of the change in grain size. Though, it is difficult to ascertain whether the annealed conditions follow the hall-petch relation due to the high aspect ratio of the grains, as it is questionable if the area-related grain size is the decisive factor. This question as well as a possible directionality of the mechanical properties will be subject to further research.

\section{Summary and conclusions}

Linear flow splitting of a HSLA steel (ZStE 500) results in an UFG microstructure in the formed flanges. The microstructure has a pancake shape with steep grain size gradients perpendicular to the flange surface. Tensile tests show a strong increase in yield strength combined with still considerable ductility. On the basis of hardness measurements the yield strength in the most severely deformed regions can be estimated at $\sim 1000 \mathrm{MPa}$. The extremely high strength of the UFG microstructure is due to a combination of grain refinement and significant work hardening. The microstructure is stable up to $300{ }^{\circ} \mathrm{C}$, while annealing at $450{ }^{\circ} \mathrm{C}$ leads to a grain refinement as the high dislocation density most likely transforms into new grain boundaries. The reduced work hardening thereby dominates the grain size effect on the strength, thus hardness and yield strength decrease, while ductility increases. At $550{ }^{\circ} \mathrm{C}$ a coarsening of the microstructure occurs and results in a nearly homogeneous microstructure and constant mechanical properties across the flange with still superior strength compared to the initial HSLA steel.

\section{Acknowledgements}

The investigations presented in this paper are supported by the German Research Foundation (DFG). The authors thank the DFG for funding the subproject $\mathrm{C} 1$ of the Collaborative Research Center 666 "Integral sheet metal design with higher order bifurcations - Development, Production, Evaluation".

\section{References}

[1] P. Groche, D. Vucic and M. Jöckel: Journal of Materials Processing Technology Vol. 183 (2007), p. 249

[2] P. Groche, J. Ringler and D. Vucic: Key Engineering Materials Vol. 344 (2007), p. 251

[3] C. Müller, T. Bohn, E. Bruder, T. Bruder, V. Landersheim, C. el Dsoki, P. Groche and D. Veleva: Materialwissenschaft und Werkstofftechnik Vol. 38 (2007), p. 842

[4] M. Furukawa, Z. Horita, M. Nemoto and T.G. Langdon: J. Mater. Sci. Vol 36 (2001), p. 2835

[5] R.Z. Valiev, R.K. Islamgaliev and I.V. Alexandrov: Prog. Mater. Sci. Vol. 45 (2000), p. 103

[6] A.P. Zhilyaev, G.V. Nurislamova, B.-K. Kim, M.D. Baró, J.A. Szpunar and T.G. Langdon: Acta Mater. Vol. 51 (2003), p. 753

[7] N. Tsuji, Y. Ito, Y. Saito and Y. Minamino: Scripta Mater Vol. 47 (2002), p. 893

[8] Y.M. Wang and E. Ma: Mater. Sci. Eng. A Vol. 375 - 377 (2004), p. 46

[9] D.H. Shin and K.-T. Park,: Mater. Sci. Eng. A Vol. 410 - 411 (2005), p. 299 